\title{
Trocas gasosas em plantas de girassol submetidas à deficiência hídrica em diferentes estádios fenológicos ${ }^{1}$
}

\author{
Gas exchange in sunflower plants subjected to water deficit at different stages of \\ growth
}

\author{
Alexandre Reuber Almeida da Silva ${ }^{2 *}$, Francisco Marcus Lima Bezerra ${ }^{3}$, Claudivan Feitosa de Lacerda ${ }^{3}$, João \\ Valdenor Pereira Filho ${ }^{3}$ e Cley Anderson Silva de Freitas ${ }^{4}$
}

\begin{abstract}
RESUMO - Este estudo avaliou as respostas das trocas gasosas do girassol quando submetido à regimes de déficit hídrico em seus diferentes estádios fenológicos. O experimento foi conduzido em Pentecoste, $\mathrm{CE}$, sob delineamento experimental em blocos casualizados, em esquema de parcelas subdivididas no tempo, com oito parcelas, três subparcelas e quatro blocos. Nas parcelas, foram avaliadas as épocas de indução do déficit hídrico nos diferentes estádios fenológicos (vegetativo, floração e formação da produção), correspondendo à ocorrência de déficit hídrico em um, dois ou três estádios, e nas subparcelas, as épocas de avaliação das características fisiológicas, que corresponderam ao término de cada fase (52; 68 e 110 dias após a semeadura - DAS). A cultura foi irrigada com uma lâmina equivalente a $100 \%$ da evapotranspiração de referência (ETo) e o déficit hídrico foi imposto com metade da lâmina que foi aplicada no tratamento controle. As épocas de avaliação influenciaram a maioria das variáveis analisadas, com exceção da eficiência intrínseca de uso da água. Os resultados de temperatura foliar e taxas de fotossíntese, transpiração, condutância estomática, concentração interna de $\mathrm{CO}_{2}$ e as eficiências instantâneas e intrínsecas do uso da água, não mostraram efeitos em relação ao nível de déficit hídrico avaliado, independentemente da época em que os mesmos foram aplicados A fotossíntese e a transpiração decresceram com o estádio de desenvolvimento da cultura, causando reduções na eficiência instantânea de uso da água. Portanto, conclui-se que a cultura pode ser irrigada com $50 \%$ da ETo, durante todo o ciclo sem danos no processo fotossintético.
\end{abstract}

Palavras-chave: Helliantus annuus L.. Plantas e água. Fotossíntese.

ABSTRACT - This study evaluated gas-exchange responses of the sunflower when subjected to water deficit at different stages of growth. The experiment was carried out at Pentecost, in the state of Ceara, in a randomized-block design of time-split plots, consisting of eight plots, three subplots and four blocks. In the plots, the periods of induction of the water deficit were evaluated at different stages of growth (vegetative, flowering and production formation), which corresponded to the occurrence of the water deficit at one, two or three stages, and in the subplots, the times of evaluation of the physiological characteristics corresponded to the end of each phase (52, 68 and 110 days after sowing, DAS). The crop was irrigated at a level equivalent to100\% of the reference for evapotranspiration (ETo), and the water deficit was imposed at half the level that was used in the control treatment. The periods of evaluation influenced most of the variables analysed, except for the intrinsic efficiency of the use of water. The results for leaf temperature and for the rates of photosynthesis, transpiration, stomatal conductance, concentration of internal $\mathrm{CO}_{2}$, and the immediate and intrinsic efficiency of the use of water, showed no effects in relation to the level of water deficit evaluated regardless of the period in which these were applied. Photosynthesis and transpiration decreased with the stage of development of the crop, causing reductions in the immediate efficiency of the use of water. It was therefore concluded that the crop can be irrigated at $50 \%$ of ETo throughout the complete cycle without damage to the process of photosynthesis.

Key words: Helliantus annuus L.. Plants and water. Photosynthesis.

\footnotetext{
*Autor para correspondência

'Recebido para publicação em 19/10/2011; aprovado em 11/07/2012

Parte da Dissertação de Mestrado apresentada pelo primeiro autor ao Programa de Pós-Graduação em Engenharia Agrícola da Universidade Federal do Ceará/UFC, Fortaleza-CE

${ }^{2}$ Departamento de Engenharia Agrícola, Centro de Ciências Agrárias, Universidade Federal do Ceará, Campus do Pici - Bloco 804, 60.455-760, Fortaleza-CE, Brasil, alexandre_reuber@hotmail.com

${ }_{3}^{3}$ Departamento de Engenharia Agrícola, Centro de Ciências Agrárias, Universidade Federal do Ceará, Fortaleza-CE, Brasil, mbezerra@ufc.br, cfeitosa@ufc.br, joao_valdenor@hotmail.com

${ }^{4}$ Instituto Federal de Educação/Ciência e Tecnologia do Ceará, Campus avançado de Tianguá, Tianguá-CE, Brasil, anderson_agrotec@yahoo.com.br
} 


\section{INTRODUÇÃO}

O girassol (Helliantus annuus L.) ocupa posição de destaque entre as cinco mais importantes espécies anuais fornecedoras de óleo no mundo, e em virtude de suas características vantajosas sob o ponto de vista agrícola e econômico, caracteriza-se por ser uma das culturas que apresenta um dos maiores índices de crescimento em termos de área plantada e quantidade produzida (CASTRO et al., 2006; SILVA et al., 2011; UCHÔA et al., 2011).

As explorações agrícolas de culturas anuais em todo Brasil são submetidas à diversos fatores ambientais adversos, potencialmente capazes de causar efeitos negativos no crescimento, desenvolvimento, produção e qualidade da produção (NASCIMENTO et al., 2011).

O déficit hídrico é um dos principais entraves responsáveis por acarretar reduções na produtividade agrícola, sobretudo, por comprometer praticamente todos os aspectos relacionados ao desenvolvimento das plantas, incluindo mudanças anatômicas, morfológicas, fisiológicas e bioquímicas, sendo que as magnitudes dos efeitos estão diretamente relacionadas à sua intensidade, duração e estádio de desenvolvimento da cultura (BEZERRA et al., 2003).

Em condições de escassez hídrica, as taxas de assimilação de $\mathrm{CO}_{2}$ são negativamente afetadas, principalmente, devido ao mecanismo de fechamento dos estômatos. Com o fechamento estomático, as plantas não só reduzem as perdas de água por transpiração, como também reduzem o suprimento de $\mathrm{CO}_{2}$ para as folhas e, como consequência, a produção de biomassa das plantas é comprometida (PAIVA et al., 2005).

As pesquisas referentes às respostas fisiológicas da cultura do girassol às condições de deficiência hídrica são pouco conclusivas. A exemplo, Cechin et al. (2010) examinaram os efeitos do estresse hídrico, seguido da reidratação nas trocas gasosas em folhas adultas e jovens de plantas de girassol e tornaram evidente que o estresse hídrico reduziu a fotossíntese, a condutância estomática e a transpiração, independente da idade da folha. Por outro lado, Carneiro (2011) avaliou os efeitos da suspensão da irrigação, também seguido da reidratação e apurou que a assimilação de $\mathrm{CO}_{2}$, assim como a concentração intercelular de $\mathrm{CO}_{2}$, não diferiu do tratamento mantido sob plena irrigação. Ainda segundo o autor supracitado, surge a necessidade de realização de estudos que objetivem induzir a cultura do girassol ao déficit hídrico ao longo de seus diferentes estádios de desenvolvimento no intuito de identificar, dentre as fases, qual é a mais sensível aos efeitos da supressão hídrica, mediante o conhecimento dos processos fisiológicos fundamentais dessa cultura, objetivando, com isso, assessorar o manejo cultural de forma mais efetiva, em face às presumíveis condições de estresse hídrico.

Uma única variável fisiológica de forma isolada não deve ser considerada quando se analisa a capacidade de tolerância à seca (NASCIMENTO et al., 2011). Por isso, segundo Nogueira et al. (2001), o ideal é que sejam analisados um conjunto de variáveis, tais, como potencial hídrico, condutância estomática, temperatura e a transpiração foliar, que são coletivamente considerados indicativos do desempenho dos vegetais diante do estresse hídrico.

Neste contexto, este estudo avaliou as respostas das trocas gasosas do girassol submetido à regimes de déficit hídrico em seus diferentes estádios fenológicos, visando identificar as possíveis estratégias utilizadas pela espécie para tolerar os efeitos do déficit hídrico imposto ao longo das fases de seu ciclo vital.

\section{MATERIAL E MÉTODOS}

O experimento foi conduzido durante o período de setembro a dezembro de 2010, na Fazenda Experimental Vale do Curu (FEVC), situada na cidade de Pentecoste no Ceará e pertencente à Universidade Federal do Ceará (UFC). As coordenadas geográficas de referência do local são latitude $3^{\circ} 49^{\prime} 25^{\prime}$ ' S, longitude 39²0'20" W e altitude média de $50 \mathrm{~m}$. O clima é do tipo BSw'h', semiárido, quente, existindo uma pequena temporada úmida. Os dados meteorológicos relativos ao período experimental foram obtidos junto à estação agrometeorológica da Fazenda Experimental Vale do Curu, situada nas imediações da área experimental (Tabela 1).

Tabela 1 - Médias mensais das variáveis climáticas registradas durante o período experimental. Pentecoste, Ceará, 2010

\begin{tabular}{lccccc}
\hline \multirow{2}{*}{ Mês } & Temperatura & Temperatura & Temperatura & UR $(\%)$ & Precipitação \\
\cline { 2 - 4 } & máxima $\left({ }^{\circ} \mathrm{C}\right)$ & mínima $\left({ }^{\circ} \mathrm{C}\right)$ & média $\left({ }^{\circ} \mathrm{C}\right)$ & & pluviométrica $(\mathrm{mm})$ \\
\hline Setembro & 37,1 & 22,2 & 29,7 & 56 & 0 \\
Outubro & 38,3 & 22,8 & 30,5 & 46 & 0 \\
Novembro & 38,1 & 22,7 & 30,4 & 50 & 0 \\
Dezembro & 36,8 & 22,8 & 29,8 & 59 & 21,8 \\
\hline
\end{tabular}

4: UR - Umidade relativa do ar 
O soloutilizado para o experimento foi da classe dos Neossolos flúvicos, textura franco-arenosa (EMPRESA BRASILEIRA DE PESQUISA AGROPECUÁRIA,
2006). As análises químicas e textural foram realizadas pelo Laboratório de Solos e Água, do Departamento de Ciências do Solo do CCA/UFC (Tabela 2).

Tabela 2 - Caracterização química e granulométrica do solo, nas camadas 0-0,20 e 0,20-0,40 m. Pentecoste, Ceará, 2010

\begin{tabular}{|c|c|c|c|c|c|c|c|c|c|c|c|}
\hline \multirow{2}{*}{ Camada (m) } & $\mathrm{pH}$ & $\mathrm{P}$ & $\mathrm{K}$ & $\mathrm{Na}$ & $\mathrm{Mg}$ & $\mathrm{Al}$ & $\mathrm{Ca}$ & M.O & Argila & Silte & Areia \\
\hline & $(-)$ & \multicolumn{3}{|c|}{$\left(\mathrm{mg} \mathrm{dm}^{-3}\right)$} & \multicolumn{3}{|c|}{$\left(\mathrm{cmol}_{\mathrm{c}} \mathrm{dm}^{-3}\right)$} & \multicolumn{4}{|c|}{$\left(\mathrm{g} \mathrm{kg}^{-1}\right)$} \\
\hline $0-0,20$ & 7,20 & 78,00 & 515,00 & 73,00 & 3,70 & 0,00 & 4,80 & 18,93 & 83 & 224 & 693 \\
\hline $0,20-0,40$ & 7,20 & 56,00 & 246,00 & 70,00 & 4,00 & 0,00 & 4,50 & 12,00 & 90 & 231 & 679 \\
\hline
\end{tabular}

O preparo do solo constou de uma aração seguida de duas gradagens cruzadas. A adubação foi baseada na análise de solo e nas exigências nutricionais da cultura conforme Aquino et al. (1993). As quantidades recomendadas foram: $60-30-30 \mathrm{~kg} \mathrm{ha}^{-1}$ de NPK (nitrogênio, fósforo e potássio). Como fonte de N, utilizou-se a uréia, de $\mathrm{P}$ o fosfato monoamônio (MAP) e de $\mathrm{K}$ o sulfato de potássio. A adubação de fundação foi realizada em covas previamente abertas, e a de cobertura foi parcelada durante o ciclo da cultura, e aplicada via água de irrigação conforme a taxa de absorção de nutrientes recomendada por Leite et al. (2005). Também foram aplicados em todos os tratamentos $10 \mathrm{~kg} \mathrm{ha}^{-1}$ de micronutrientes na forma comercial do fertilizante mineral FTE BR-12 (9\% Zn; 1,8\% B; 0,85\% $\mathrm{Cu} ; 3 \% \mathrm{Fe} ; 2,1 \% \mathrm{Mn}$; e 0,10\% Mo).

A cultivar utilizada no experimento foi a Multissol, no espaçamento entre as fileiras de $0,9 \mathrm{~m}$ e de $0,25 \mathrm{~m}$ entre as plantas nas fileiras. O desenvolvimento da cultura foi dividido em três estádios fenológicos, vegetativo (da semeadura até o estádio inicial de floração), floração (do final do estádio anterior até a fase de floração final), e formação da produção (do final do estádio anterior até a colheita), segundo Schneiter e Miller (1981).

O delineamento experimental utilizado foi o de blocos casualizados, em esquema de parcelas subdivididas no tempo (split-plot in time), com oito parcelas, três subparcelas e quatro blocos. Nas parcelas, com área de 16,2 $\mathrm{m}^{2}$ (2,7 m x 6,0 m), foram avaliados os tratamentos que foram definidos em função da época de indução do déficit hídrico nos diferentes estádios fenológicos da cultura, correspondendo à ocorrência de déficit hídrico em um, dois ou três estádios, assim agrupados: T1: tratamento em que a cultura não sofreu nenhum déficit hídrico nos três estádios fenológicos (controle); T2: a cultura sofreu déficit hídrico no estádio de formação da produção; T3: déficit hídrico no estádio de floração; T4: déficit hídrico nos estádios de floração e formação da produção; T5: déficit hídrico no estádio vegetativo; T6: déficit hídrico nos estádios vegetativo e formação da produção; T7: déficit hídrico nos estádios vegetativo e floração; T8: déficit hídrico nos três estádios fenológicos. As subparcelas foram constituídas por as épocas de avaliação das características fisiológicas, que corresponderam ao término de cada estádio (aos 52; 68 e 110 dias após a semeadura - DAS).

A área total ocupada pelo experimento foi de $864 \mathrm{~m}^{2}$ (28,8 m x 30,0 m), composta por 128 linhas de plantio. Cada linha útil de plantas ocupou a área de 5,4 m², contendo vinte e quatro plantas cada.

A cultura foi irrigada pelo método localizado, com o sistema do tipo gotejamento sobre linha. Os gotejadores eram do tipo autocompensantes, com vazão média de $3,75 \mathrm{~L} \mathrm{~h}^{-1}$ a uma pressão de serviço de $150 \mathrm{kPa}$, e foram espaçados de $0,5 \mathrm{~m}$ na linha com um gotejador por duas plantas. No início de cada linha lateral de irrigação foi instalado um registro, a fim de controlar a quantidade de água aplicada nas unidades experimentais.

Após a semeadura, a área experimental foi irrigada diariamente com uma lâmina equivalente a $100 \%$ da evapotranspiração de referência, estimada através da evaporação medida em um Tanque Classe A, a fim de garantir a uniformidade do estande até o início e diferenciação dos tratamentos, que se deu aos 21 dias após a semeadura (DAS).

Aevapotranspiração de referência(ETo) foi estimada através da equação 1 (BERNARDO et al., 2006):

$$
E T o=E C A \times K t
$$

em que, ETo - Evapotranspiração de referência estimada através do Tanque Classe A (mm); ECA - Evaporação medida através do Tanque Classe A (mm); Kt - Coeficiente de ajuste do tanque (adimensional).

O coeficiente de ajuste do tanque $(\mathrm{Kt})$ foi calculado através da equação 2, proposta por Snyder (1992):

$$
K t=0,482+0,24 \ln (F)-0,00037 U+0,0045 U R
$$


em que, Kt - Coeficiente de ajuste do tanque (adimensional); F - Menor distância do centro do tanque ao limite da bordadura (m); U - Velocidade do vento $\left(\mathrm{km} \mathrm{dia}^{-1}\right)$; UR - Umidade relativa do ar (\%).

A irrigação total necessária foi calculada pela equação 3, proposta por Bernardo et al. (2006):

$$
I T N=\frac{L I \times P A M}{C U D}
$$

em que, ITN - Irrigação Total Necessária (mm); LI - Lâmina de Irrigação, referente à evapotranspiração de referência (ETo) (mm); PAM - Percentagem de Área Molhada (Valor adotado 0,40); CUD - Coeficiente de Uniformidade de Distribuição de água do sistema de irrigação (Obtido em avaliação de campo, CUD =0,90).

Já o tempo de irrigação foi calculado a partir da equação 4:

$$
T_{I}=\frac{I T N \times A_{P}}{N e f \times q_{g}}
$$

em que, $\mathrm{T}_{\mathrm{I}}$ - Tempo de irrigação (h); ITN - Irrigação Total Necessária $(\mathrm{mm}) ; \mathrm{A}_{\mathrm{p}}$ - Área da faixa de plantio $\left(\mathrm{m}^{2}\right) ;(\mathrm{Ap}=6$ $\left.\times 0,9=5,4 \mathrm{~m}^{2}\right)$; Nef - Número de emissores na faixa de plantio $(\mathrm{Nef}=12) ; \mathrm{q}_{\mathrm{g}}$ - Vazão do gotejador, $\mathrm{L} \mathrm{h}^{-1}\left(\mathrm{q}_{\mathrm{g}}=3,75 \mathrm{~L} \mathrm{~h}^{-1}\right)$.

As unidades experimentais submetidas ao déficit hídrico ao longo do ciclo da cultura receberam 50\% da lâmina de água aplicada no Tratamento 1 (controle). Após o início da diferenciação dos tratamentos, a quantidade de água aplicada em cada tratamento passou a ser reposta a cada dois dias e as lâminas aplicadas continuaram tendo por base a ETo.
Durante o período de condução do experimento, sempre que necessário, procederam-se tratos culturais e controle fitossanitário, seguindo recomendações de Leite et al. (2005).

Foram realizadas medições da temperatura foliar e das taxas de fotossíntese (A), transpiração (E), condutância estomática $\left(\mathrm{g}_{\mathrm{s}}\right)$ e concentração interna de $\mathrm{CO}_{2}\left(\mathrm{C}_{\mathrm{I}}\right)$ em folhas totalmente expandidas, ao término de cada estádio fenológico (aos 52; 68 e 110 DAS) utilizando-se analisador de gases infravermelho portátil (Irga), modelo Li-6400XT (Portable Photosynthesis System - LI) da LICOR. Com os dados de trocas gasosas foram determinadas a eficiência instantânea de uso da água $\left(\mathrm{A} \mathrm{E}^{-1}\right)$ e a eficiência intrínseca

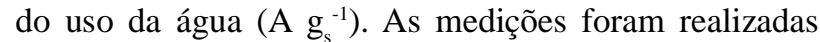
sempre no período da manha.

Os dados foram submetidos à análise da variância pelo teste F a 1 e 5\%. Quando verificado efeito significativo, as médias obtidas nos tratamentos foram comparadas pelo teste de Tukey ( $p \leq 0,05)$, nessas análises foi utilizado o software estatístico ASSISTAT versão 7.6 BETA.

\section{RESULTADOS E DISCUSSÃO}

O resumo das análises das variâncias das respostas fisiológicas do girassol referente aos efeitos dos tratamentos e das épocas de avaliação para os resultados obtidos com os dados de fotossíntese (A), transpiração (E), condutância estomática $\left(\mathrm{g}_{\mathrm{s}}\right)$, concentração interna de $\mathrm{CO}_{2}$ $\left(\mathrm{C}_{\mathrm{I}}\right)$, temperatura foliar $\left(\mathrm{T}_{\mathrm{F}}\right)$, eficiência instantânea de uso da água $\left(\mathrm{AE}^{-1}\right)$ e eficiência intrínseca de uso da água $\left(\mathrm{Ag}_{\mathrm{s}}{ }^{-1}\right)$ está apresentado na Tabela 3.

Tabela 3 - Resumo da análise de variância para as variáveis fisiológicas do girassol, submetido à deficiência hídrica nos diferentes estádios fenológicos. Pentecoste, Ceará, $2010^{5}$

\begin{tabular}{lcccccccc}
\hline \multicolumn{1}{c}{ F.V. } & GL & \multicolumn{7}{c}{ Teste F } \\
\cline { 3 - 9 } & & $\mathrm{A}$ & $\mathrm{E}$ & $\mathrm{g}_{\mathrm{s}}$ & $\mathrm{C}_{\mathrm{I}}$ & $\mathrm{T}_{\mathrm{F}}$ & $\mathrm{A} \mathrm{E}^{-1}$ & $\mathrm{Ag}_{\mathrm{s}}{ }^{-1}$ \\
\hline Blocos & 3 & 0,17 & 0,89 & 0,98 & 0,86 & 1,96 & 0,99 & 0,94 \\
Tratamentos (T) & 7 & $0,79^{\mathrm{ns}}$ & $0,51^{\mathrm{ns}}$ & $0,78^{\mathrm{ns}}$ & $0,45^{\mathrm{ns}}$ & $0,44^{\mathrm{ns}}$ & $0,78^{\mathrm{ns}}$ & $0,51^{\mathrm{ns}}$ \\
Resíduo (T) & 21 & - & - & - & - & - & - & - \\
Épocas (E) & 2 & $139,01^{* *}$ & $11,86^{* *}$ & $20,75^{* *}$ & $7,31^{* *}$ & $28,75^{* *}$ & $178,89^{* *}$ & $0,81^{\mathrm{ns}}$ \\
T x E & 14 & $0,86^{\mathrm{ns}}$ & $0,80^{\mathrm{ns}}$ & $0,73^{\mathrm{ns}}$ & $0,96^{\mathrm{ns}}$ & $0,53^{\mathrm{ns}}$ & $0,92^{\mathrm{ns}}$ & $0,85^{\mathrm{ns}}$ \\
Resíduo (E) & 48 & - & - & - & - & - & - & - \\
CV - T (\%) & - & 12,59 & 9.79 & 24,84 & 4,91 & 2,40 & 10,55 & 27,74 \\
CV - E (\%) & - & 9,67 & 9,10 & 27,91 & 4,05 & 3,37 & 7,98 & 26,78 \\
\hline
\end{tabular}

5: FV - Fontes de variação; GL - Graus de liberdade; CV - Coeficientes de variação; A - Fotossíntese $\left(\mu \mathrm{mol} \mathrm{m}^{-2} \mathrm{~s}^{-1}\right) ; \mathrm{E}^{-}$Transpiração $\left(\mathrm{mmol} \mathrm{m}^{-2} \mathrm{~s}^{-1}\right)$; $\mathrm{g}$

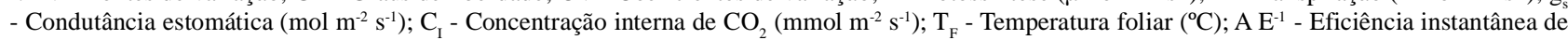
uso da água $\left(\mathrm{mmol} \mathrm{CO}_{2} \mathrm{~mol}^{-1} \mathrm{H}_{2} \mathrm{O}\right) ; \mathrm{A} \mathrm{g}_{\mathrm{s}}{ }^{-1}$ - Eficiência intrínseca de uso da água $\left(\mathrm{mmol} \mathrm{m}^{2} \mathrm{~s}^{-1} \mathrm{H}_{2} \mathrm{O}\right)$; ${ }^{\text {ns }}$ - Não significativo, ${ }^{* *}$ - Significativo a $1 \%$ pelo teste F 
Com relação às trocas gasosas verificaramse diferenças significativas $(\mathrm{p} \leq 0,01)$, apenas para os efeitos principais do fator épocas de avaliação, para todas as variáveis analisadas, com exceção da eficiência intrínseca de uso da água. Todavia, estes fatores em estudo (tratamentos e épocas de avaliação) variaram de modo independente entre si, e não foi verificada significância entre as interações (Tabela 3).

Resultados semelhantes a estes foram encontrados por Carneiro (2011) em pesquisa sobre o impacto do estresse hídrico através da suspensão total da irrigação sobre as trocas gasosas no girassol, onde evidenciou que a assimilação de $\mathrm{CO}_{2}$, assim como a concentração intercelular de $\mathrm{CO}_{2}$, não diferiu do tratamento controle (irrigadas diariamente) até o quinto dia após a interrupção do suprimento de água. Para este mesmo autor, a condutância estomática e a transpiração também apresentaram pequena variação entre os tratamentos.

Os resultados da presente pesquisa são divergentes dos obtidos por Cechin et al. (2010) quando constataram que após seis dias de estresse hídrico, imposto por meio da suspensão total do fornecimento de água, as variáveis fisiológicas fotossíntese, condutância estomática e transpiração nas folhas de girassol foram reduzidas em função do estresse imposto.

A exposição das espécies vegetais ao déficit hídrico de forma suficientemente lenta e gradual, como foi realizado neste estudo, induz nas plantas a ativação de uma complexa série de adaptações morfofisiológicas de aclimatação ao estresse, no intuito de minimizar os efeitos negativos da escassez de água (SANTOS; CARLESSO, 1998). As sequelas do estresse hídrico sobre os vegetais são muito variadas e dependem da intensidade, bem como da duração do estresse ao qual a planta está sendo submetida (MENDES et al., 2007).

Observa-se que a ausência de efeitos significativos do déficit hídrico sob as variáveis analisadas são indicativos de que as lâminas de irrigação que foram aplicadas nos tratamentos submetidos ao déficit ao longo dos diferentes estádios de desenvolvimento (50\% daETo) foram suficientes para garantir um status hídrico a nível celular da planta comparáveis aos do tratamento irrigado sem restrição hídrica (100\% da ETo), fato que, possivelmente, ocorreu devido à adoção de ambos os níveis de irrigação proporcionarem a manutenção do potencial hídrico foliar e, consequentemente, da turgescência das células guardas dos estômatos, uma vez que os danos provocados pelo estresse hídrico variam conforme a intensidade de sua ocorrência (LIMA et al., 2010). O que condiz com informações de Silva et al. (2010a), ao relatarem que plantas de feijão-caupi também submetidas à reposição de $50 \%$ da água perdida por evapotranspiração não apresentaram lesões no processo fotossintético, refletido pelas inalterações nas trocas gasosas quando comparadas à reposição de $100 \%$ da água perdida por evapotranspiração.
A deficiência hídrica, quando imposta de forma controlada pode resultar em melhores eficiências fotossintéticas (SANTOS; CARLESSO, 1998).

Respostas não estomática do girassol mediante ao déficit hídrico não acarretam efeitos na eficiência fotoquímica do fotossistema II (CARNEIRO, 2011). O que está de acordo com informações de Tezara et al. (2008), ao observarem que em plantas desta espécie, quando a fotossíntese é inibida em decorrência do déficit hídrico, existe uma fração dos centros de reação do fotossistema II que permanecem abertos e são capazes de realizar todo trabalho fotoquímico, sem, contudo provocar alterações significativas nas trocas gasosas, o que provavelmente ocorreu nesse estudo.

Estes resultados levam a crer que a cultura do girassol pode também ter adotado outras estratégias visando aumentar sua tolerância diante das condições de restrições hídricas, estratégias estas não analisadas na presente pesquisa como, por exemplo, o ajustamento osmótico, mecanismo que consiste na capacidade desenvolvida pelas plantas mediante ao estresse provocado por déficit hídrico de acumular ativamente açúcares, ácidos orgânicos e íons no citosol, assegurando a manutenção do potencial hídrico, com redução de seu potencial osmótico e, por conseguinte, conservando o turgor de suas células próximo ao nível ótimo (NEPOMUCENO et al., 2001).

Segundo esses autores, quando o turgor celular é mantido, processos como a condutância estomática, a assimilação de $\mathrm{CO}_{2}$ e a expansão dos tecidos vegetais são parciais ou totalmente mantidas, ajustes estes que têm sido observados no girassol. O que contrapõe as informações de Cechin et al. (2010) e Carneiro (2011), os quais confirmaram que o potencial hídrico foliar diminuiu à medida que o período de déficit de água aumentou em plantas de girassol, evidenciando que as reduções no potencial hídrico refletem diretamente as mudanças que ocorreram no potencial osmótico decorrentes da restrição hídrica.

Vale ressaltar que medidas momentâneas de trocas gasosas podem não refletir o autêntico comportamento fisiológico da planta frente à condição de estresse ao longo de todo dia e, portanto, carecem ser avaliadas com certa precaução (SILVA et al., 2010b). A este respeito Taiz e Zeiger (2009), reportam que no curso diário natural ocorre desbalanço entre a água absorvida pelo sistema radicular e a transpirada pelas folhas, independente da condição de suprimento hídrico, em função da oscilação da demanda evaporativa da atmosfera ao longo do dia. Desse modo, é provável que em alguma hora do dia fossem detectadas diferenças significativas entre os tratamentos de déficits de irrigação, uma vez que as leituras foram realizadas apenas no período da manha.

Outra hipótese que poderia explicar o fato das trocas gasosas em plantas de girassol não terem sido influenciadas pelas distintas estratégias de manejo da irrigação impostas 
ao longo dos diferentes estádios de desenvolvimento seria o fato de se ter adotado durante a condução do experimento uma irrigação de alta frequência (dois dias), embora o volume de água aplicado na condição de estresse tenha sido reduzido. Irrigações mais frequentes evitam o esgotamento excessivo da zona radicular e eliminam o estado de escassez de água na planta (BERNARDO et al., 2006). Isso é condizente com informações de Paiva et al. (2005), ao verificarem que os efeitos do déficit de água no solo acabam não exercendo influências nos processos fotossintéticos dos vegetais quando se adota uma irrigação de alta frequência, uma vez que nestas condições, um melhor estado hídrico na planta é assegurado, de tal forma que as respostas das trocas gasosas nas plantas cultivadas sob condições de déficit hídrico, acabam seguindo a mesma tendência das plantas sem restrição hídrica.

A comparação das médias das variáveis relacionadas às trocas gasosas para o efeito isolado do fator épocas de avaliação pode ser observada na Tabela 4. Constata-se que a maior taxa fotossintética foi verificada aos 52 DAS, diferindo significativamente das demais $(\mathrm{p} \leq 0,05)$, seguida da avaliação aos 68 e 110 DAS que também diferiram estaticamente entre si $(\mathrm{p} \leq 0,05)$, de tal forma que as taxas fotossintéticas foram decrescendo ao longo das distintas etapas fenológicas da cultura, com uma redução de aproximadamente $33,51 \%$, ao se comparar os valores extremos (Tabela 4).

$\mathrm{Na}$ medida em que as folhas crescem, sua capacidade para produzir fotoassimilados aumenta até o alcance da maturidade, que consiste em seu crescimento final, fase na qual as taxas fotossintéticas começam então a decrescer. Folhas velhas e senescentes eventualmente tornam-se amarelas e são incapazes de realizar a fotossíntese, pois a clorofila é degradada e o cloroplasto passa a perder sua funcionalidade (TAIZ; ZEIGER, 2009). O que pode explicar, em parte, as reduções estatisticamente significativas observadas nas taxas fotossintéticas e na eficiência instantânea de uso da água, com o avanço do ciclo cultural (Tabela 4). Tais observações estão condizentes com resultados obtidos por Neves et al. (2009), ao relatarem que observações semelhantes foram constatadas no feijão-de-corda e por Oliveira Júnior et al. (2007), em genótipos de milho doce e comum.

Segundo Kozlowski e Pallardy (1997), as variações que ocorrem nas taxas fotossintéticas dos vegetais em função das distintas etapas fenológicas estão ainda associadas às várias modificações que ocorrem nas folhas em nível morfológico, anatômico e fisiológico, em decorrência do processo de expansão foliar, onde se menciona: o desenvolvimento de tecidos foliares internos, frequência de estômatos e tricomas, síntese de clorofilas, aumento da condutância estomática, capacidade de transporte de elétrons, síntese de proteínas e atividade da Rubisco, além da redução da respiração mitocondrial.

Com relação à transpiração, o maior valor encontrado foi verificado na avaliação aos $68 \mathrm{DAS}$, cujo valor foi superior estatisticamente $(\mathrm{p} \leq 0,05)$ àqueles obtidos aos 110 e 52 DAS, evidenciando que neste estádio fenológico a cultura possui maior demanda hídrica (Tabela 4). Estimando os percentuais médios do total de água consumida nos diferentes períodos de crescimento da cultura do girassol, presume-se que aproximadamente $20 \%$ do total são utilizados durante o estádio vegetativo, 55\% durante a floração, restando os demais $25 \%$ para o período de formação da produção, que corresponde às fases de enchimento e maturação dos aquênios (FOOD AND AGRICULTURE ORGANIZATION, 2011).

Em relação à condutância estomática, foi observado que o maior valor médio $\left(1,42 \mathrm{~mol} \mathrm{~m}^{-2} \mathrm{~s}^{-1}\right)$ foi registrado para a avaliação realizada aos 52 DAS, sendo superior estatisticamente $(\mathrm{p} \leq 0,05)$ apenas aos valores observados aos 110 DAS $\left(0,90 \mathrm{~mol} \mathrm{~m}^{-2} \mathrm{~s}^{-1}\right)$, com redução de aproximadamente $37 \%$, ao se comparar os valores extremos (Tabela 4). Embora não tenham sido detectadas diferenças significativas na condutância estomática entre os 52 e 68 DAS ( $p \leq 0,05$ ), observase que a mesma se comportou de forma semelhante à fotossíntese, sugerindo que os declínios das taxas fotossintéticas estejam relacionados com o fechamento

Tabela 4 - Fotossíntese, Transpiração, Condutância estomática, Concentração interna de $\mathrm{CO}_{2}$, Temperatura foliar e Eficiência instantânea de uso da água do girassol aos 52, 68 e 110 DAS. Pentecoste, Ceará, $2010^{6}$

\begin{tabular}{ccccccc}
\hline DAS & $\mathrm{A}$ & $\mathrm{E}$ & $\mathrm{g}_{\mathrm{s}}$ & $\mathrm{C}_{\mathrm{I}}$ & $\mathrm{T}_{\mathrm{F}}$ & $\mathrm{AE}^{-1}$ \\
\hline 52 & $31,90 \mathrm{a}$ & $16,33 \mathrm{~b}$ & $1,42 \mathrm{a}$ & $267,56 \mathrm{a}$ & $33,12 \mathrm{~b}$ & $1,95 \mathrm{a}$ \\
68 & $28,89 \mathrm{~b}$ & $17,64 \mathrm{a}$ & $1,29 \mathrm{a}$ & $257,72 \mathrm{~b}$ & $34,71 \mathrm{a}$ & $1,64 \mathrm{~b}$ \\
110 & $21,21 \mathrm{c}$ & $15,86 \mathrm{~b}$ & $0,90 \mathrm{~b}$ & $265,03 \mathrm{a}$ & $35,23 \mathrm{a}$ & $1,33 \mathrm{c}$ \\
\hline DMS & 1,59 & 0,91 & 0,20 & 6,46 & 0,70 & 0,07 \\
\hline
\end{tabular}

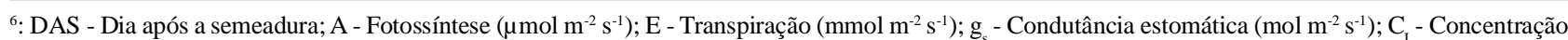

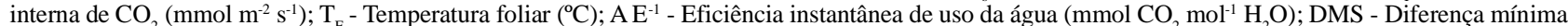
significativa; Médias seguidas de letras iguais nas colunas não diferem estatisticamente entre si pelo teste de Tukey a $5 \%$ 
parcial dos estômatos refletidos pelas reduções na condutância estomática (MACHADO et al., 2002).

A concentração interna de $\mathrm{CO}_{2}$ registrou o maior valor médio $\left(267,56 \mathrm{mmol} \mathrm{m}^{-2} \mathrm{~s}^{-1}\right)$ para a avaliação realizada aos 52 DAS, sendo superior estatisticamente $(\mathrm{p} \leq 0,05)$ apenas dos valores observados aos 68 DAS $\left(257,72 \mathrm{mmol} \mathrm{m}^{-2} \mathrm{~s}^{-1}\right)$ (Tabela 4). A ampliação da concentração interna de $\mathrm{CO}_{2}$ entre os 68 e 110 DAS são indicativos de que não houve restrição na aquisição de $\mathrm{CO}_{2}$ por parte da cultura ao longo dos diferentes estádios de desenvolvimento, porém, quando o mesmo alcançava as células do mesófilo, o processo de fixação durante a fase de carboxilação foi comprometido (HABERMANN et al., 2007), fatos que podem estar relacionados à degradação do aparelho fotossintético em resposta ao processo de senescência foliar dos tecidos.

A respeito da temperatura foliar, observa-se tendência de elevação dos valores ao longo dos estádios de desenvolvimento da cultura, de tal forma que o valor máximo $\left(35,23{ }^{\circ} \mathrm{C}\right)$ foi registrado aos 110 DAS, o qual não diferiu estatisticamente $(\mathrm{p} \leq 0,05)$ daquele apontado aos $68^{\circ}$ DAS $\left(34,71{ }^{\circ} \mathrm{C}\right)$. Em contrapartida, quando esta variável foi analisada aos 52 DAS, constatou-se o menor dos valores $\left(33,12^{\circ} \mathrm{C}\right)$, e este valor diferiu estatisticamente dos demais $(\mathrm{p} \leq 0,05)$ (Tabela 4$)$.

A inferioridade estatística da temperatura foliar aos 52 DAS deve-se às maiores taxas fotossintéticas registradas nesta época. Tal comportamento pode ser explicado por Tribuzy (2005), quando reportou que a fotossíntese é um dos mecanismos fisiológicos mais compassivos ao estresse térmico decorrente de elevadas temperaturas e, presume-se que o mesmo é apontado como o principal fator capaz de limitar a fixação de carbono nas distintas etapas do processo fotossintético, uma vez que pequenas oscilações de temperatura nos órgãos vegetais podem acarretar amplos efeitos sobre as atividades bioquímicas das folhas.

Aos 52 DAS pode-se considerar que a cultura do girassol utilizou a água de forma mais eficiente, em função do maior valor médio de eficiência instantânea de uso da água registrado nesta época de avaliação $(1,95$ $\mu \mathrm{mol} \mathrm{CO} \mathrm{mol}^{-1} \mathrm{H}_{2} \mathrm{O}$ ), indicando que maior quantidade de $\mathrm{CO}_{2}$ foi absorvida, em detrimento da menor perda de água, diferindo estatisticamente $(\mathrm{p} \leq 0,05)$ dos valores verificados aos 68 DAS (1,64 mmol $\left.\mathrm{CO}_{2} \mathrm{~mol}^{-1} \mathrm{H}_{2} \mathrm{O}\right)$ e aos $110 \mathrm{DAS}$ (1,33 mmol CO $\mathrm{mol}^{-1} \mathrm{H}_{2} \mathrm{O}$ ) (Tabela 4). Supostamente, estas diferenças são indícios dos efeitos da própria fase de crescimento sobre a fotossíntese, em decorrência da variação existente na demanda por fotoassimilados para os órgãos drenos ao longo do ciclo (MACHADO et al., 2002), de tal forma que com o avanço das fases floração e enchimento de aquênios a fotossíntese é reduzida. Em contrapartida, a transpiração reduziu apenas na segunda fase (68 DAS), voltando a alcançar aos 110 DAS valores estatisticamente similares aos observados aos 52 DAS.

A indução de déficit hídrico de forma mais severa poderia ter conduzido a diferenças mais significativas nos resultados obtidos. Desta forma, sugere-se que estudos posteriores sejam conduzidos sob diferentes intensidades de déficits hídricos ao longo dos diferentes estádios de desenvolvimento da cultura, avaliando também variáveis como o potencial hídrico, bem como o curso diário das trocas gasosas, a fim de melhor caracterizar o comportamento fisiológico do girassol em resposta às limitações hídricas.

\section{CONCLUSÕES}

1. A temperatura foliare as taxas de fotossíntese, transpiração, condutância estomática, concentração interna de $\mathrm{CO}_{2} \mathrm{e}$ as eficiências instantâneas e intrínsecas do uso da água observadas em plantas de girassol, não mostram efeitos significativos em relação ao nível de déficit hídrico, independentemente da época em que foram aplicados:

2. As épocas de avaliação influenciam a maioria das variáveis analisadas relacionadas às trocas gasosas, com exceção da eficiência intrínseca de uso da água que não evidencia variação nos estádios fenológicos considerados;

3. As trocas gasosas do girassol toleram o déficit hídrico, indicando que a cultura pode ser irrigada com $50 \%$ da ETo, nas diferentes fases de seu desenvolvimento sem danos no processo fotossintético;

4.O manejo da irrigação com déficit na cultura do girassol resulta em maior eficiência de uso da água por parte da cultura.

\section{REFERÊNCIAS}

AQUINO, A. B. et al. Recomendações de adubação e calagem para o estado do Ceará. Fortaleza: Imprensa Universitária, 1993. 248 p.

BERNARDO, S. et al. Manual de irrigação. Viçosa: Editora UFV, 2006. $625 \mathrm{p}$.

BEZERRA, F. M. L. et al. Feijão caupi e déficit hídrico em suas fases fenológicas. Revista Ciência Agronômica, v. 34, n. 01, p. 5-10, 2003.

CARNEIRO, M. M. L. C. Trocas gasosas e metabolismo antioxidativo em plantas de girassol em resposta ao déficit hídrico. 2011. 42 f. Dissertação (Mestrado em Ciências) Universidade Federal de Pelotas, Pelotas, 2011.

CASTRO, C. de et al. Boro e estresse hídrico na produção do girassol. Revista Ciência agrotécnica, v. 30, n. 02, p. 214-220, 2006. 
CECHIN, I. et al. Differential responses between mature and young leaves of sunflower plants to oxidative stress caused by water deficit. Revista Ciência Rural, v. 40, n. 06, p. 1290-1294, 2010.

EMPRESA BRASILEIRA DE PESQUISA AGROPECUÁRUIA. Centro Nacional de Pesquisa de Solos. Sistema Brasileiro de Classificação de Solos. Rio de Janeiro: Embrapa Solos, 2006. 412 p.

FOOD AND AGRICULTURE ORGANIZATION. Crop Water Information: Sunflower. Disponível em: <http://www.fao.org/ nr/water/cropinfo_sunflower.html>. Acesso em: 25 ago. 2011.

HABERMANN, G. et al. $\mathrm{CO}_{2}$ assimilation, photosynthetic light response curves, and water relations of 'Pêra' sweet orange plants infected with Xylella fastidious. Brazilian Journal of Plant Physiology, v. 15, n. 02, p. 79-87, 2003.

KOZLOWSKI, T. T.; PALLARDY, S. G. Physiology of woody plants. 2. ed. San Diego: Academic Press, 1997. 427 p.

LEITE, R. M. V. B. de C. et al. (Ed.). Girassol no Brasil. Londrina: Embrapa Soja, 2005. 641 p.

LIMA, M. de A. et al. Trocas gasosas em folhas de sol e sombreadas de cajueiro anão em diferentes regimes hídricos. Revista Ciência Agronômica, v. 41, n. 04, p. 654-663, 2010.

MACHADO, E. C. et al. Variação sazonal da fotossíntese, condutância estomática e potencial da água na folha de laranjeira 'Valência'. Revista Scientia Agricola, v. 59, n. 01, p. 53-58, 2002.

MENDES, F. da S. et al. Níveis de prolina e carboidratos solúveis totais em folhas de mogno (Swietenia macrophylla King R.A) induzidas ao estresse hídrico e a reidratação. Revista Brasileira de Biociências, v. 05, n. 02, p. 939-941, 2007.

NASCIMENTO, S. P. do et al. Tolerância ao déficit hídrico em genótipos de feijão-caupi. Revista Brasileira de Engenharia Agrícola e Ambiental, v. 15, n. 08, p. 853-860, 2011.

NEPOMUCENO, A. L. et al. Tolerância à seca em plantas. Revista Biotecnologia Ciência \& Desenvolvimento, v. 23, n. 01, p. 12-18, 2001.

NEVES, A. L. R. et al. Trocas gasosas e teores de minerais no feijão-de-corda irrigado com água salina em diferentes estádios. Revista Brasileira de Engenharia Agrícola e Ambiental, v. 13, p. 873-881, 2009. Suplemento.

NOGUEIRA, R. J. M. C. et al. Alterações na resistência à difusão de vapor das folhas e relações hídricas em aceroleiras submetidas a déficit de água. Revista Brasileira de Fisiologia Vegetal, v. 13, n. 01, p. 75-87, 2001.

OLIVEIRA JÚNIOR, L. F. G. de. et al. Diferenças fisiológicas entre genótipos de milho doce (su- 1 ) e milho comum durante o desenvolvimento. Revista Scientia Agrária, v. 08, n. 04, p. 351-356, 2007.

PAIVA, A. S. et al. Condutância estomática em folhas de feijoeiro submetido a diferentes regimes de irrigação. Revista Brasileira de Engenharia Agrícola, v. 25, n. 01, p. 161-169, 2005.

SANTOS, R. F.; CARLESSO, R. Déficit hídrico e os processos morfológico e fisiológico das plantas. Revista Brasileira de Engenharia Agrícola e Ambiental, v. 02, n. 03, p. 287-294, 1998.

SCHNEITER, A. A.; MILLER, J. P. Description of sunflower growth stages. Crop Science, v. 21, n. 06, p. 901-903, 1981.

SILVA, A. R. A. da et al. Desempenho de cultivares de girassol sob diferentes lâminas de irrigação no Vale do Curu, CE. Revista Ciência Agronômica, v. 42, n. 01, p. 57-64, 2011.

SILVA, C. D. S. e et al. Curso diário das trocas gasosas em plantas de feijão-caupi submetidas à deficiência hídrica. Revista Caatinga, v. 23, n. 04, p. 7-13, 2010a.

SILVA, V. A. et al. Resposta fisiológica de clone de café Conilon sensível à deficiência hídrica enxertado em porta-enxerto tolerante. Revista Pesquisa Agropecuária Brasileira, v. 45, n. 05, p. 457 - 464, 2010 b.

SNYDER, R. L. Equation for evaporation pan to evapotranspiration conversions. Journal of Irrigation and Drainage, v. 118, n. 06, p. 977-980, 1992.

TAIZ, L.; ZEIGER, E. Fisiologia vegetal. 4. ed. Porto Alegre: Artmed, 2009. $819 \mathrm{p}$

TEZARA, W. et al. Partitioning of photosynthetic electron flow between $\mathrm{CO}_{2}$ assimilation and $\mathrm{O}_{2}$ reduction in sunflower plants under water deficit. Photosynthetica, v. 46, n. 01, p. 127- 134, 2008.

TRIBUZY, E. S. Variações da temperatura foliar e do dossel e o seu efeito na taxa assimilatória de $\mathrm{CO}_{2}$ na Amazônia Central. 2005. 84 f. Tese (Doutorado em Ecologia de Agroecossistemas) - Universidade de São Paulo, Piracicaba, 2005.

UCHÔA, S. C. P. et al. Adubação de potássio em cobertura nos componentes de produção de cultivares de girassol. Revista Ciência Agronômica, v. 42, n. 01, p. 8-15, 2011. 